\title{
Apresentação
}

\section{QUEM EDUCA O EDUCADOR? A FORMAÇÃO HUMANA TECENDO-SE NAS RELAÇÕES ENTRE TRABALHO, MOVIMENTOS SOCIAIS E EDUCAÇÃO1}

\author{
Maria Clara Bueno Fischer ${ }^{2}$ \\ Célia Regina Vendramini ${ }^{3}$
}

Apresentamos aos leitores e leitoras o segundo volume do número temático da Revista Trabalho Necessário intitulado Trabalho, Movimentos Sociais e Educação. A resposta à chamada da TN 33 superou nossas expectativas. Assim, organizamos este volume com a mesma temática visando acolher outras relevantes contribuições para ampliar a visibilidade de práticas e estratégias político-educativas de lutas, sindicatos e movimentos sociais organizados na atualidade, bem como outras ações coletivas de caráter emancipatório.

Neste segundo volume, as contribuições dos e das autores/as nos remetem para a temática da formação humana que se dá na experiência histórica. Como convite à interlocução com o/as autores/as e com os/as leitores/as retomamos aqui a Tese III de Marx sobre Feurbach:

\begin{abstract}
A teoria materialista sobre a modificação das circunstâncias e da educação esquece que as circunstâncias são modificadas precisamente pelos homens e que o próprio educador precisa ser educado. Ela tem, por isso, de dividir a sociedade em duas partes, a primeira das quais está colocada acima da sociedade. A coincidência entre a alter [ação] das circunstâncias e a atividade ou automodificação humanas só pode ser apreendida e racionalmente entendida como prática revolucionária (MARX, 2007, p. 533-4).
\end{abstract}

\footnotetext{
${ }_{1}^{1}$ Publicado em 27/09/2019. DOI: https://doi.org/10.22409/tn.17i34.p38041

2Doutora em Educação pela Universidade de Nottingham, Inglaterra. Professora da Universidade Federal do Rio Grande do Sul, na linha de pesquisa Trabalho, Movimentos Sociais e Educação. Bolsista PQ CNPq. Email:mariaclara180211@gmail.com Orcid: https://orcid.org/0000-0003-2289-5282.

${ }^{3}$ Doutora em Educação pela Universidade Federal de São Carlos. Professora da Universidade Federal de Santa Catarina, na linha de pesquisa Trabalho, Educação e Política. Bolsista PQ CNPq. E-mail: celia.vendramini@ufsc.br Orcid: https://orcid.org/0000-0001-9600-2868.
} 
O ser, o estar e o agir humanos são condicionados pelas circunstâncias históricas, mas não as determinam. Ao mesmo tempo que são por elas formados, as (trans) formam. É disso que se trata quando buscamos apreender relações entre trabalho, movimentos sociais e educação. Somos instigados a compreender os processos sociais nos quais diversos coletivos, na luta organizada estão se aprendendo como sujeitos sociais, éticos, culturais e políticos. Muitas interrogações emanam daí: como a experiência de trabalho e dos movimentos sociais - da luta pela terra; da luta contra processos escravizadores; da luta pela emancipação do trabalho explorado, das lutas identitárias étnicas, raciais e de gênero - estão formando sujeitos que, ao mesmo tempo em que denunciam os desumanos modos de vida do capitalismo, anunciam, em suas práticas de luta e educativas, outros modos com cariz emancipatório ? ${ }^{3}$ Como tais processos estão tecendo tramas de experiências de classe na nossa latino américa? Frente à expropriação e exploração capitalista da natureza que outras práticas contrárias a esta lógica estão sendo gestadas pelos movimentos e lutas sociais? Que experiências de educação emancipatórias estão acontecendo nestes contextos?

Presenciamos na experiência latino-americana, algumas das quais são analisadas neste número temático, práticas educativas radicais que, vinculadas às lutas sociais, se erguem contra todas as formas de opressão econômico-culturais. De natureza anticapitalista, formam sujeitos capazes de compreender as raízes das relações sociais capitalistas com o concomitante desenvolvimento de ações individuais e coletivas orientadas para aboli-las. É preciso entender a realidade como uma totalidade histórica criada pelos seres humanos e que, portanto, demanda a superação de práticas que reproduzem e recriam as próprias condições que os oprimem como seres humanos. Ricas reflexões sobre a experiência de educação do MST, presentes neste número temático, contribuem para ampliarmos nosso entendimento de uma educação "para além do capital".

Paulo Freire nos legou importante contribuição ao afirmar que é preciso estar com o mundo, e não simplesmente no mundo. Estar no mundo significa

\footnotetext{
${ }^{4}$ As reflexões de Roseli Caldart - Pedagogia do Movimento Sem Terra: escola é mais do que escola (2000) e de Miguel Arroyo - Outros Sujeitos, Outras Pedagogias (2014) buscam responder estas perguntas.
} 
umas práxis limitada e não crítica, porque não estabelecemos espontaneamente, relações que explicam a constituição dos fenômenos. É a práxis crítica, através da luta coletiva e de concomitantes processos educativos emancipatórios que possibilitam a experiência refletida, a qual contribui estrategicamente para a superação das relações sociais de exploração e opressão capitalistas. Neste sentido, muito temos nos interrogado e, ao mesmo tempo, aprendido sobre objetivos, formas de organização e de educação de diversos movimentos sociais e lutas coletivas atuais. Há, no entanto, muito ainda a se interrogar acerca da estratégica necessidade da unidade na diversidade com vistas à emancipação de todas as formas de opressão. Nesta direção, somos instigados a refletir, neste volume, sobre o racismo e as lutas antirracistas no Brasil e sobre questões teóricas acerca da diversidade e unidade na análise implicadas na categoria classe social.

Reinventar a escola também tem sido uma tarefa dos movimentos sociais em aliança com intelectuais-educadores orgânicos à classe trabalhadora. Além dos movimentos camponeses que, no caso do Brasil, tem feito uma longa luta por instituir um projeto de Educação do Campo, o movimento indígena tem dado lições de luta contra hegemônica no campo da educação. Suas ações na luta por um Ensino Superior que Ihes faça sentido, respeitando suas epistemologias, problematizam visões eurocêntricas e colonizadoras do pensamento dos povos indígenas. Um dos artigos traz instigantes reflexões sobre este tema. Em que medida tais reflexões e proposições podem contribuir com uma reflexão mais ampla acerca da colonização do pensamento latino-americano?

Outro desafio colocado pelas atuais práticas político-educativas dos movimentos sociais diz respeito ao princípio educativo presente em práticas produtivas que se pautam pela apropriação coletiva dos meios de produção e por relações de autogestão no contexto do capitalismo. Qual o seu alcance em termos de prefigurações de um futuro de autogestão da economia e da vida em sociedade? Quais suas contradições? Como se fazem presentes mediações de primeira e segunda ordem (Mészáros, 2011)? Como seus protagonistas as têm enfrentado? Algumas pistas podem ser inferidas a partir da análise de experiências históricas de autogestão. A trajetória de Paul Singer, pensador e militante da economia solidária no Brasil, particularmente 
sua contribuição para pensar a economia solidária como uma experiência pedagógica na perspectiva da autogestão, toma um lugar neste número da Trabalho Necessário evidenciando mais uma faceta da complexidade das formas de trabalho em que estão envolvidos os trabalhadores e trabalhadoras e de como seus intelectuais orgânicos as concebem.

Retomando a Tese III de Marx, "coincidência entre a alter [ação] das circunstâncias e a atividade ou automodificação humanas só pode ser apreendida e racionalmente entendida como prática revolucionária", e finalizando as problematizações desta apresentação, podemos pensar que a prática revolucionária, como a ocorrida com a Revolução Cubana, foi um marco histórico de automodificação humana radical. No entanto, como discutem nossos colegas cubanos em artigo sobre organização e participação popular, é uma tarefa permanente. A pergunta que se pode fazer é: como manter viva, permanente e criativa uma revolução socialista?

Tais problematizações acima indicadas têm o objetivo de contribuir com o desenvolvimento de interlocuções ativas entre autores/as e leitores/as, bem como convidar a todos para a leitura, reflexão e debate. A seguir apresentamos, de forma breve, os diferentes artigos que compõem este número da revista.

A seção de Artigos do Número Temático é composta de nove artigos, sendo um internacional.

O primeiro artigo, de Caridad Pérez García, Royana Paredes Díaz e Jesús Jorge Pérez García, analisa uma experiência de organização e participação popular que vem ocorrendo em Cuba. O texto, intitulado Organización y participación popular en Cuba: aportes desde el grupo comunitario de educación ambiental, nos auxilia a pensar sobre os lugares e formas da educação popular para e na organização e participação popular na busca de solução de problemas sociais e ambientais vividos pelo povo num país socialista. Chama a atenção nas ações coletivas de uma cooperativa agrícola, objeto de análise, a incorporação de ação educativa ambiental dirigida para o conjunto da sociedade,

O artigo de Sandra Luciana Dalmagro e Caroline Bahniuk, intitulado $A$ classe trabalhadora e suas lutas no capitalismo contemporâneo: sínteses do debate marxista, contribui para enfrentar os desafios históricos e atuais de 
organização da classe trabalhadora. Com base nas categorias classe e trabalho, dentro do aporte marxista, as autoras se debruçam sobre as mobilizações e movimentos sociais nas últimas décadas no contexto do capitalismo contemporâneo e as profundas transformações nos processos produtivos. Analisam a classe nos seus aspectos objetivos e subjetivos e apreendem a totalidade que a constitui, mesmo diante do reconhecimento de sua diversidade. Segundo as autoras, "o que confere unidade à diversidade é a condição de trabalhadores explorados e oprimidos".

Ivonei Andrioni e Edson Caetano, no artigo Feiras agroecológicas como contraponto ao projeto do capital, analisam a experiência da feira Canteiros de Comercialização Sociossolidária e Agroecológica (CANTASOL), de trabalhadores de um assentamento de reforma agrária no estado do Mato Grosso. O objetivo é contrapor as feiras agroecológicas, as quais buscam, segundo os autores, a reprodução ampliada da vida, às feiras livres, cujo objetivo é a reprodução ampliada do capital. O estudo evidencia que, além da estratégia de sobrevivência, a iniciativa se constitui como uma forma de contestação às relações de trabalho conformadas no modo de produção capitalista, ao ser resultado de uma produção a partir de técnicas de reduzido impacto ao meio ambiente, sem exploração da força de trabalho alheia e com eliminação do atravessador. A feira também é vista como um meio de organizar o enfrentamento político e a luta por direitos.

A experiência de formação política da Escola Nacional Florestan Fernandes - ENFF, de iniciativa do Movimento dos Trabalhadores Rurais Sem Terra, é abordada no artigo de Alessandro Santos Mariano e José Claudinei Lombardi, intitulado: O trabalho na práxis formativa da Escola Nacional Florestan Fernandes: uma escola construída pela e para a classe trabalhadora. O foco está na concepção e método formativo da Escola dirigido para a formação de militantes, quadros e dirigentes de movimentos e organizações populares do Brasil e outros países. O texto está organizado em cinco partes: contexto que deu origem à ENFF; a escolha de seu patrono - Florestan Fernandes; fundamentos e concepção de formação de quadros; método pedagógico a partir da matriz do trabalho; currículo e cursos de formação ofertados. Segundo seus autores, a Escola "é fruto da solidariedade de classe 
e, na atual conjuntura, tem o desafio da resistência ativa em conjunto com as demais organizações".

As crianças sem-terrinha ganham atenção no artigo de Vanessa Gonçalves Dias, Dynara Martinez Silveira e Daniel do Nascimento. O texto aborda o Brincar, sorrir, lutar por reforma agrária popular: a experiência de auto-organização das crianças sem-terrinha do MST/RS. A partir de uma reflexão sobre as concepções de infância, os autores focam na infância no MST e, particularmente, na experiência de auto-organização das crianças no Encontro Regional das Crianças Sem-Terrinha no Rio Grande do Sul. As reflexões elaboradas pelos autores indicam que a auto-organização e participação das crianças têm provocado novas estratégias educativas do MST, ao articular a experiência do brincar com as lutas pela reforma agrária. Observam que as crianças reivindicam transporte seguro, estrutura escolar, autonomia pedagógica nas escolas, denunciam o fechamento de escolas e exercitam a auto-organização e cooperação.

Povos indígenas e seu movimento de luta pela efetivação do direito coletivo à educação superior no território latino-americano, de autoria de Soledad Bech Gaivizzo, trata da luta do movimento indígena na América Latina pelo seu direito coletivo à educação superior no final da década do século XX. Discute sobre a constituição do marco jurídico-legal internacional, considerada uma conquista histórica pelos indígenas. Tal marco possibilitou a criação de outros modelos de Ensino Superior em que a interculturalidade emerge como um projeto ético-político e epistêmico. Segunda a autora, "a análise da demanda dos povos permitiu, nesse contexto, observar que o cerne da luta de seus povos busca garantir um modelo de ensino específico e diferenciado, situado geograficamente próximo à comunidade, voltado essencialmente para o seu projeto de desenvolvimento, de modo a atender os sujeitos representantes destas comunidades".

O movimento de economia solidária tem entre seus principais intelectuais militantes Paul Singer, falecido em 2018. Cláudio Nascimento e Aline Mendonça, no artigo Paul Singer e a pedagogia da autogestão na economia solidária apresentam os esforços teóricos, políticos e práticos que Paul Singer desenvolveu em sua trajetória pessoal e profissional, no Brasil e no mundo, para contribuir no avanço da autogestão e da economia solidária, 
entendida como ato pedagógico e como estratégia de desenvolvimento, tendo no horizonte o socialismo. Trazem, portanto, uma análise da contribuição de Singer para a reflexão e elaboração dos princípios pedagógicos orientadores do movimento da economia solidária.

Jacqueline Botelho em seu texto Racismo e luta antirracista no brasil: uma análise necessária para o avanço da estratégia anticapitalista analisa a contribuição do antirracismo para a luta anticapitalista no Brasil. Apoiando-se na historiografia crítica, denuncia o mito da democracia racial e desenvolve um argumento central ao longo do texto: "a luta antirracista não assume uma posição secundária em relação à luta de classes, mas a qualifica e informa, sendo o açoite do negro pela exploração do trabalho, e o racismo autorizado, elementos que impõem novos limites à consciência de classe e ao movimento negro organizado“.

O objetivo do artigo Educação profissional rural versus educação profissional do campo: uma análise gramsciana da atuação do SENAR e dos movimentos sociais camponeses é analisar a disputa ideológica entre as concepções de Educação Profissional Rural e a Educação do Campo. Os autores Pedro Clei Sanches Macedo e Ramofly Bicalho analisam a utilização desses conceitos pelo Sistema Nacional de Aprendizagem Rural na política de formação voltada para o agronegócio e na atuação dos movimentos sociais na defesa do PRONERA. Gramsci é o referencial teórico e metodológico que orienta a pesquisa da qual originou-se o artigo. Os autores defendem que a análise dos fundamentos de tais concepções é central para a construção do projeto alternativo de formação profissional dos movimentos camponeses.

A Revista Trabalho Necessário traz uma Entrevista com Fabiana Batista, historiadora e militante do Movimento dos Trabalhadores Sem Teto (MTST). Na Luta por moradia e contra a precarização da vida, Fabiana atua na área de comunicação, em âmbito nacional, faz trabalhos de base em Niterói e ajuda na organização de uma cozinha comunitária em São Gonçalo. A entrevista foi realizada por Luiz Augusto de Oliveira Gomes, em julho de 2019. O número que ora apresentamos conta ainda com três Artigos de Demanda Contínua. O artigo de Amanda Moreira da Silva, intitulado $A$ uberização do trabalho docente no Brasil: uma tendência de precarização no séc. $X X$, traz uma densa reflexão sobre as condições do trabalho docente na 
atualidade, a partir de casos concretos de uma rede estadual e uma municipal de São Paulo. A autora aponta que, em função do desemprego crescente e da massificação do discurso de empreendedorismo, cada vez mais trabalhadores se submetem a contratos precários e flexíveis, num processo que se aprofunda ainda mais com a implantação da contrarreforma trabalhista, constituindo o que se pode chamar de "uberização" do trabalho docente, expressa pelo crescimento do número de trabalhadores eventuais, e que já atinge a Educação Básica como um todo. Mas, se este quadro apresenta-se tão grave, Amanda destaca, em suas considerações finais, que muitas destas iniciativas de precarização do trabalho docente só não foram concretizadas graças à organização dos trabalhadores da educação junto aos seus sindicatos. Isto, a nosso ver, confirma e reforça a relevância de trabalhos como este serem publicados pela revista Trabalho Necessário.

O artigo Reformas do ensino médio e trabalhista: possíveisimplicações para educação profissional técnica de nível médio, das pesquisadoras Tatiane Cimara dos Santos Medeiros e Daniela Oliveira Ramos dos Passos, analisa como as reformas influenciam nesta modalidade de ensino - a Educação Profissional Técnica de Nível Médio. Trata-se de uma pesquisa exploratória que apresenta ainda resultados parciais, pois se encontra em andamento. A riqueza do texto está na compilação, em que apresenta uma boa síntese e no diálogo que estabelece com a rica bibliografia sobre o tema, estimulando o debate. Em seus resultados sinaliza o processo de flexibilização dos direitos da classe trabalhadora, em que o currículo não só reduz os gastos públicos, mas acaba, pela composição que apresenta, prejudicando a formação dos trabalhadores, na medida em que atende às necessidades do sistema capital, para responder a crise construída por ele e pelas políticas neoliberais que buscam engendrar na educação brasileira.

Os pesquisadores Leonardo Dorneles Gonçalves e Simone Gonçalves da Silva nos brindam com o artigo Trabalho e Educação: debates em tornodo princípio educativo e das políticas educacionais para o ensino médio de jovens e adultos. Valendo-se de pesquisas no campo do materialismo histórico, indicam que as formas de oferta da EJA em nível médio, as políticas educacionais para a área, seus mecanismos de certificação, formação aligeirada e diminuição do acesso aos conteúdos representativos dos 
conhecimentos científicos e culturais representam acentuado retrocesso em termos civilizatórios, sobretudo para os jovens da classe trabalhadora.

Na seção Teses e Dissertações, apresentamos dois trabalhos. A tese de Joana D’Arc Vaz, intitulada A Educação Profissional no contexto das relações de cooperação entre Brasil-Moçambique: o protagonismo de empresas brasileiras traz como questão central a cooperação Sul-Sul e o protagonismo dos empresários brasileiros em Moçambique, como parte da política externa dos governos Lula e Dilma Rousseff, tendo como recortes os períodos de 2003-2015 e a Educação Profissional no contexto desta cooperação. A autora buscou refletir sobre os interesses que estavam em disputa, por parte dos diferentes atores envolvidos na política da educação, e especificamente na Educação Profissional; porque a Educação Profissional compõe as estratégias do capital em Moçambique, transformando- se em instrumento de combate à pobreza na lógica do desenvolvimento do país. Em síntese, que papel joga o Brasil (o Estado Brasileiro) nessa cooperação, não estando desarticulada do contexto sócio-político-econômico contemporâneos, de desenvolvimento do sistema capital e qual o lugar do trabalho, como categoria ontológica, no processo de formação humana.

A dissertação de Janaina Gulart Oliveira Queiroz, intitulada As condições de vida, de trabalho e de escolarização dos migrantes nordestinos da construção civil na UFSC, reflete sobre a vida de trabalhadores migrantes nordestinos da construção civil que trabalham no Campus central da Universidade Federal de Santa Catarina. Baseada no estudo de autores clássicos e contemporâneos que analisam as contradições entre capital, trabalho e escolarização, e sustentada numa pesquisa de campo cuidadosa, a autora identifica que "o trabalho ou a ausência dele tem sido fator principal no deslocamento para a produção da vida social e busca pela superação da condição de pobreza da classe trabalhadora", e é a partir desta condição que se pode entender o seu processo de escolarização - paradoxalmente, a presença na universidade não é o bastante para garantir-lhes o acesso a uma educação de qualidade: cerca de $78 \%$ deles têm o ensino fundamental incompleto e deixaram a escola para trabalhar - em condições precárias, o que reatualiza uma condição histórica da classe trabalhadora no Brasil. 
A seção Memória e Documentos traz, neste número temático, um pouco da história/experiência do Arquivo Geral dos Trabalhadores, apresentado por Maria Cláudia Pereira da Silva. Iniciado nos anos 1990, como Arquivo do SINTTEL-Rio (Sindicato dos Trabalhadores em Telecomunicações do Rio de Janeiro) reuniu, desde então, inúmeros documentos que recuperam a história de organização sindical da categoria, como elemento vivo e importante da luta dos trabalhadores. Nos últimos anos ampliou-se para receber outras coleções relacionadas às lutas da classe trabalhadora brasileira. O que encontraremos aqui é uma pequena mostra deste acervo que, como bem disse a autora, citando Le Goff (1990), faz parte de um passado que deve ser salvo para servir o presente e o futuro. Que saibamos sorvê-lo!

\section{Referências}

ARROYO, M. Outros sujeitos, outras pedagogias. Rio de Janeiro: Vozes, 2014.

CALDART, R. Pedagogia do Movimento Sem Terra: escola é mais do que escola Rio de Janeiro: Vozes, 2000

MARX, K. Ad Feuerbach. IN: MARX, K, ENGELS, F. A ideologia alemã: crítica da mais recente filosofia alemã Feuerbach, B. Bauer e Stirner, e do socialismo alemão em seus diferentes profetas 1845-1846. São Paulo: Boitempo Editorial, 2007, p.533-535.

MÉSZÁROS, I. Para além do capital. São Paulo: Boitempo, 2011. 